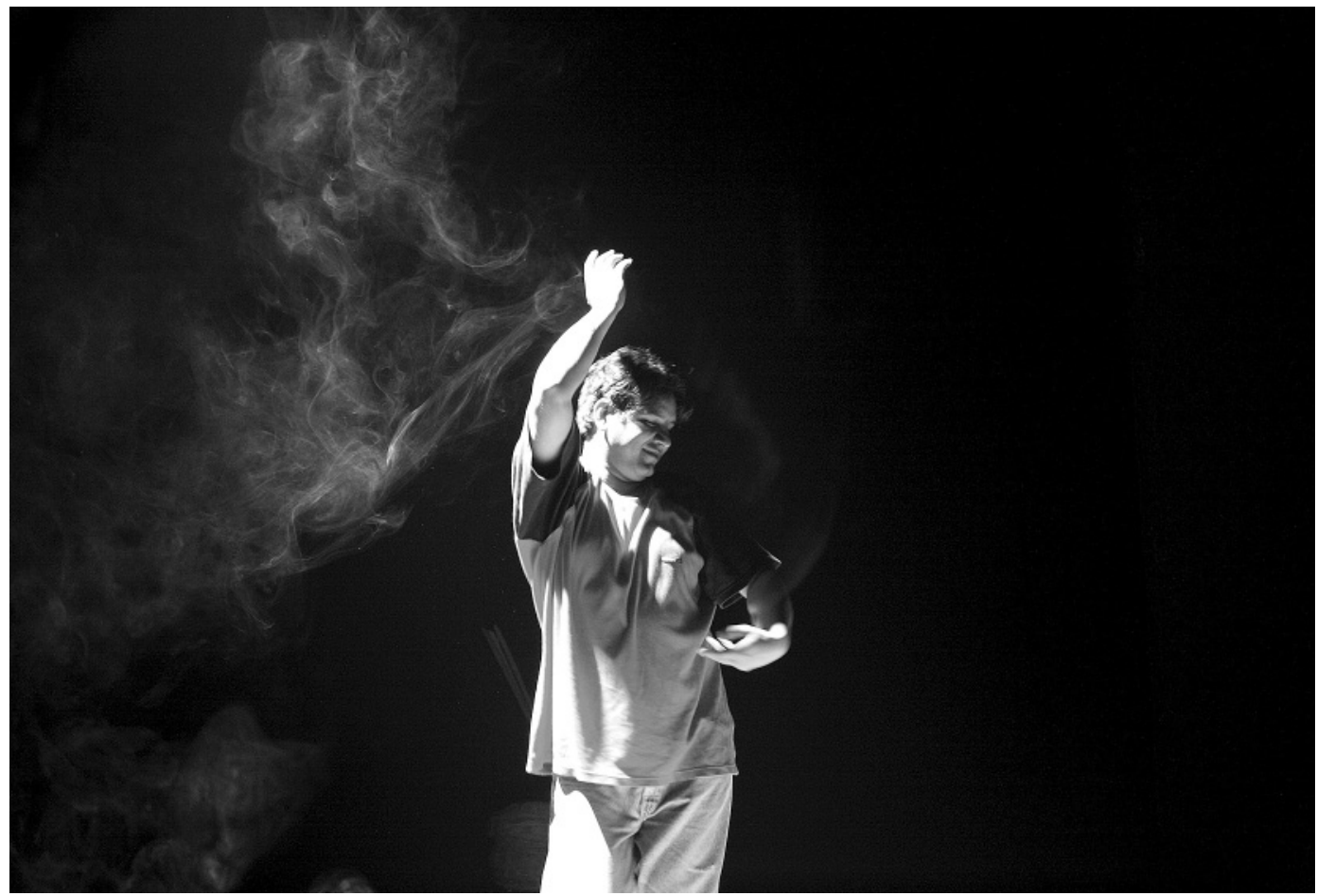

\title{
0 teatro indiano em inglês Com uma referência especial à cena teatral contemporânea em Mumbai ${ }^{1}$
}

\author{
Deepa Punjani
}

Num artigo sobre o teatro indiano em inglês, Adil Jussawalla, um conhecido poeta e crítico, começava por fazer uma citação assumidamente manipulada do famoso criador teatral e activista, Safdar Hashmi: "Quer se esteja num teatro de língua bengali, marata, canará, telugu, tamil, garhwali ou até mesmo nessa coisa impossivel chamada teatro indiano em inglês, é preciso ver teatro de outras línguas...". Ao destacar as palavras a negrito, Jussawalla estava a chamar a atenção para o facto de, apesar das pobres imitações das farsas e comédias oriundas do West End ou da Broadway e desse hibrido que é a comédia "Hinglesa"2 , o teatro inglês na Índia ter conseguido deixar as suas marcas. Baseado na sua própria experiência das peças inglesas que tinha visto na İndia e dos

dramaturgos que conhecera, Jussawalla sublinhava assim a importância do género, por muito peculiar ou "impossivel" que lhe pudesse parecer.

Já passou algum tempo sobre aquele artigo; pelo menos, o tempo suficiente para eu própria acrescentar algo às palavras de Safdar Hashmi, que ainda conservam a ironia suficiente para todos aqueles que têm sido observadores atentos desta realidade teatral. Atrevo-me, assim, a acrescentar um breve parêntesis àquela citação, falando antes de "essa coisa (im)possivel", uma vez que me proponho caracterizar a situação da cena teatral contemporânea em Mumbai, em tudo aquilo que se prende com o teatro indiano em inglês. As alterações que este tipo de teatro vem conhecendo desde os anos cinquenta não são necessariamente dramáticas, mas apresentamse como expressivas dos diferentes caminhos explorados. De modo a debater quais têm sido essas alterações e a isolar a experiência do teatro indiano em inglês, convoquei para este artigo um conjunto de peças - umas mais antigas, outras mais recentes - bem como os responsáveis pela sua composição e/ou realização cénica.

Esclareça-se que não é minha ambição oferecer uma perspectiva cronológica ou histórica deste género teatral. Do mesmo modo, esta não pretende ser uma abordagem exaustiva. 0 que gostaria de fazer seria analisar aquilo que assegura uma identidade própria ao teatro em língua inglesa na Índia. Em primeiro lugar, é importante esclarecer do que estamos a falar. Será que teatro indiano em inglês é a mesma coisa que teatro inglês na Índia? Ou serão duas realidades distintas? Ainda que as consideremos distintas, existirão sempre algumas sobreposições, especialmente no caso de adaptações e traduções mais bem sucedidas. Mas uma vez que as peças estrangeiras que habitualmente são levadas à cena têm, de qualquer modo, um apelo internacional, capaz de transcender fronteiras socioculturais e geográficas, não terão as duas realidades o mesmo sentido?

Um público indiano achará tão difícil acompanhar o inglês quinhentista e seiscentista de Shakespeare como um qualquer cidadão britânico actual. Mas Shakespeare em adaptação tem-se revelado tão maleável como o barro.
${ }^{1}$ Mumbai, também conhecida como Bombaim, é a capital do estado indiano de Maharashtra. Com uma população na ordem dos 13 milhões de habitantes é a cidade mais populosa da İndia (N.T.).

${ }^{2}$ A expressão origina usada pela autora é "Hinglish", que parece cruzar Hindi com English (N.T.).

\section{Deepa Punjani}

é crítica de teatro e professora. É a editora responsável por um boletim electrónico dedicado ao teatro em Mumbai: www.mumbaitheatre guide.com. 
E quanto a outros dramaturgos internacionais como Ibsen, Pirandello, Beckett, Havel e muitos outros? A resposta é que têm sido realizadas na İndia algumas bem sucedidas produções em inglês das suas peças. Ao mesmo tempo, uma peça com uma língua mais especifica como o marata pode revelar-se estrangeira para uma companhia indiana que esteja habituada a representar em inglês.

Por isso, a minha opinião sobre esta questão é que sejam quais forem as nossas definições, elas serão sempre relativas à produção em causa. Razão pela qual seria injusto e provinciano sugerir que as peças estrangeiras não podem ser consideradas como parte do teatro indiano em língua inglesa. Tudo depende da peça e do modo como foi encenada e representada. Por exemplo, a encenação de A gaivota, de Tchekov, por Jaimini Pathak, em 2006, seguia de perto o texto original - talvez com algumas pequenas alterações - e revelou-se uma excelente experiência teatral. No sentido contrário, fiquei particularmente desanimada com a leitura cénica de Gidahe, de Vijay Tendulkar - traduzida como Os abutres, a partir da peça marata original - realizada por membros experimentados do mais respeitado de todos os agrupamentos de língua inglesa na cidade - o Theatre Group. Assim, qualquer produção boa e credivel em inglês, parta ela de uma peça originalmente indiana ou estrangeira, apresenta-se justificadamente como parte da cena teatral indiana em lingua inglesa.

De um modo mais específico, contudo, teatro indiano em inglês refere-se a todas as vozes indianas que escrevem em inglês. Foram os dramaturgos, afinal de contas, quem moldaram e definiram este género, conferindo-Ihe novos contornos. Mas ao contrário do romance indiano em inglês, que atingiu a sua maturidade em meados do século $X X$, através dos contributos de escritores como R. K. Narayan, Rajá Rao e Mulk Raj Anand, a peça inglesa na Índia começou por ser sobretudo uma importação do Ocidente. Embora seja possivel referir algumas excepções - tais como Os perseguidos (The Persecuted), de Krishna Mohan Banerjee, uma peça do século XIX, ou, mais tarde, já em meados do século XX, uma peça chamada Asilo (Asylum), de Erna Vatchanghandy, o teatro inglês em Mumbai foi durante muito tempo dominado por dramaturgos estrangeiros, produções ao estilo da Broadway e as já referidas comédias "hinglesas" popularizadas por Bharat Dabholkar.

Existem pelo menos cinco a seis razões para este desenvolvimento relativamente tardio da peça indiana em língua inglesa: razões históricas - práticas e de atitude -razões que se prendem com a aceitabilidade e o conforto, e, finalmente, com a apatia. As razões históricas são fáceis de explicar: o teatro inglês na Índia começou por ser o domínio de ingleses, que construíram teatros para assegurar o seu próprio divertimento e para a recolha de dinheiro para a caridade. Quanto às razões de ordem prática e ligadas a questões de atitude, convirá recordar que uma peça, ao contrário de um romance, precisa do teatro para transmitir toda a sua complexidade. Claro que é possível ler uma peça, mas nunca será a mesma experiência vê-la. Mais uma vez, é possivel ter uma peça extraordinária sobre a experiência indiana, mas o problema surge se os actores disponíveis não estiverem enraizados nessa experiência. 0 mesmo argumento pode ser alargado à própria peça: na qualidade de um dramaturgo e actor urbano, falante de inglês, como é que eu posso ultrapassar a barreira da língua para comunicar a experiência especifica de uma cultura regional ou até mesmo local? Mas podemos complicar ainda mais as coisas: se a língua inglesa é falada de modo diferente em todo o mundo, essa diversidade torna-se ainda maior num país tão vasto e com tantas diferenças como a Índia. A verdade é que existem tantas variantes de "inglês" indiano como línguas e dialectos indianos.

É um facto cientificamente confirmado que a nossa língua mãe tende a exercer uma influência considerável no modo como uma segunda língua como o inglês é entendida, aprendida e utilizada. Num cenário urbano como Mumbai, pode ser mais fácil aprender e falar a língua, mas mesmo ai basta escutar com atenção para descobrir as diferenças subjacentes. Em Mumbai, existia, a dada 

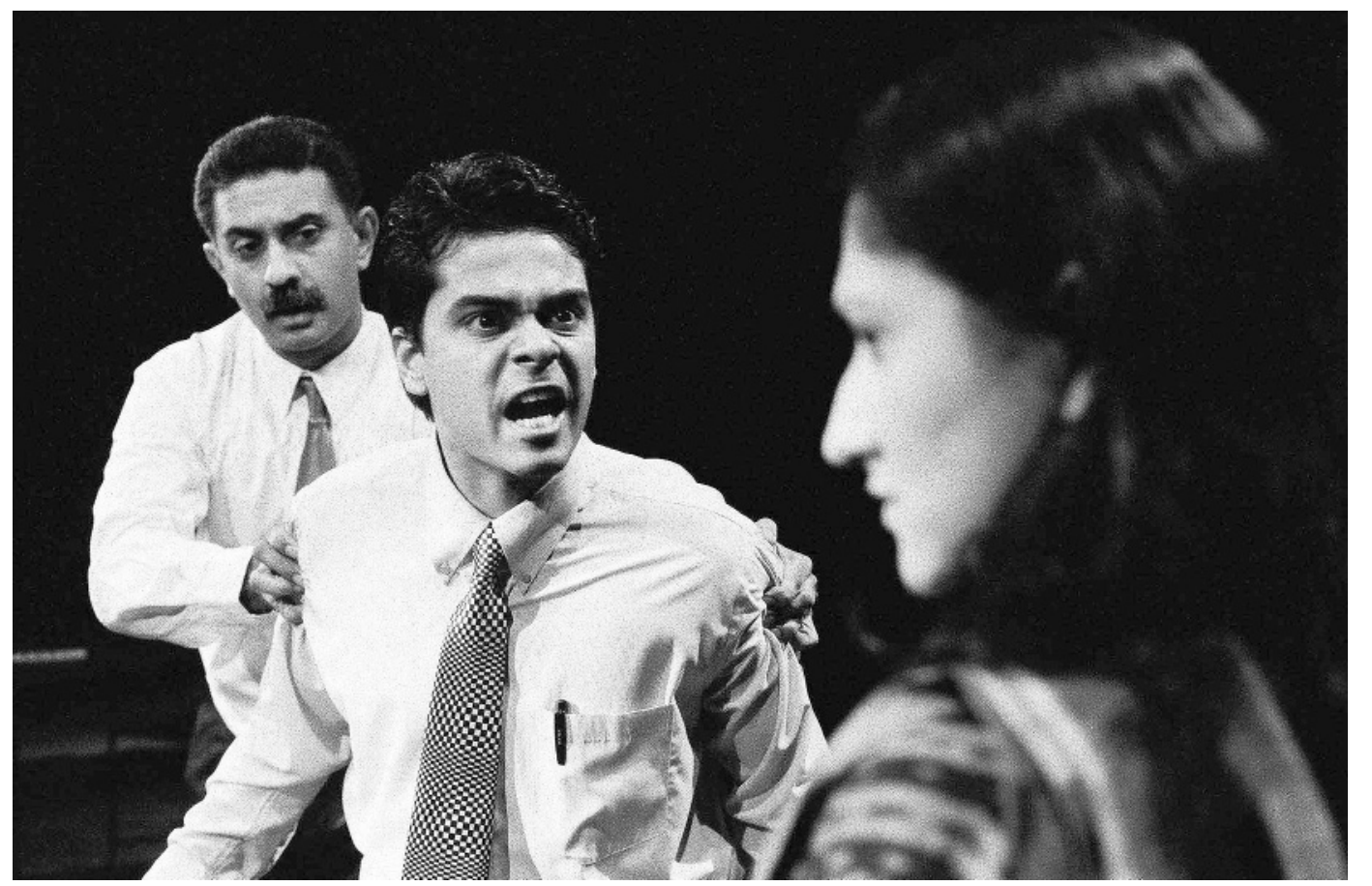

altura, uma clara divisão entre as pessoas do sul e os que viviam nos subúrbios, e o teatro não constituía qualquer excepção. 0 tipo de teatro praticado no sul da cidade, dominado pela lingua inglesa, era frequentemente visto como elitista, um entendimento que, embora exagerado, não se afigura inteiramente sem fundamento.

Em termos de atitude, o indiano médio e muitas das pessoas ligadas ao teatro, jovens e velhos, raramente se esforçam por sair do microcosmo da sua realidade imediata. Consequentemente, as suas peças revelam-se muitas vezes superficiais, insuficientemente aferidas ao real e, nalguns casos, repletas de estereótipos. Este problema sério não afecta unicamente o teatro indiano em inglês, mas manifesta-se talvez de forma mais aguda neste género teatral.

0 sucesso de uma peça indiana em língua inglesa depende em larga medida da aceitação do uso do inglês como meio de comunicação e, consequentemente, como modo de estabelecer uma ligação com as minúcias dos aspectos socioculturais, que integram o guião e o espectáculo. Mais complicada é a questão de uma personagem para a qual o inglês é uma língua estrangeira. Um modo sábio e sem dúvida mais indicado de contornar este problema é o de utilizar uma qualquer língua ou dialecto regional juntamente com o inglês. Muitos dos dramaturgos actuais têm adoptado esta abordagem.

Por último, a apatia: se no Ocidente, o teatro não é uma profissão fácil de se ter, a história mostra-se ainda pior na Índia. Em resultado disso, muitos dos seus profissionais, sejam eles dramaturgos, encenadores, actores ou desenhadores de som ou de luz, confrontam-se frequentemente com problemas tão básicos como a falta de financiamento, de recursos e de infra-estruturas.

0 espaço é um dos principais problemas. A maior parte dos agrupamentos indianos de língua inglesa na cidade dispõe unicamente de dois sítios onde podem representar, o Teatro Prithvi e o Centro Nacional para as Artes do Espectáculo (CNAE). Naturalmente, torna-se muito difícil arranjar datas disponiveis. Este problema é agravado pelo elevado custo de aluguer exigido por uma instituição como o CNAE, que pratica valores considerados proibitivos pelas companhias mais jovens. Enquanto alguns encenadores, como Sunil Shanbag, tentam fazer face a este problema criando peças que possam ser representadas em qualquer sítio, outros, como Atul Kumar, da The Company Theatre, desenvolveram o conceito de teatro doméstico. Muitos dos jovens têm explorado espaços alternativos, como galerias e bares, para a representação das suas peças.

Mas o facto é que, não obstante este conjunto de dificuldades, a escala da actividade teatral numa cidade como Mumbai é inimaginável. Apesar do recente aparecimento de muitas novas peças, o teatro indiano em inglês é apenas uma pequena parte da multilingue paisagem teatral da cidade.

Gostaria de começar por referir alguns dos dramaturgos que escreveram peças indianas originais em língua inglesa e que se encontram entre os nomes mais importantes da cena teatral contemporânea na İndia. Nem todos eles trabalham em Mumbai, embora as suas peças tenham sido ai representadas.

Partap Sharma iniciou a sua carreira como dramaturgo nos anos sessenta. As suas peças mais recentes são Zen Kahta (2005) e Sammy! (2006). Foram ambas encenadas por Lillette Dubey, director da companhia Prime Time Theatre. Estas duas peças de Sharma apresentam problemas tanto a nivel textual como cénico: tudo parece muito conveniente. Ambas funcionam bem ao nível do divertimento, mas deixam pouco espaço para qualquer tipo de crítica ou de discussão.

As três peças seguintes fazem parte dos primeiros exemplos de um teatro indiano em inglês verdadeiramente original, sendo frequentemente referidas como responsáveis pela criação de uma experiência indiana viva e intensa. O Senhor Behram (Mister Behram), do Dr. Gieve Patel, escrita nos anos oitenta, desenrola-se em torno da personagem que lhe dá titulo, um advogado altamente respeitado no Raj britânico, cuja vida é destruída quando revela um amor considerado não natural pelo seu genro 


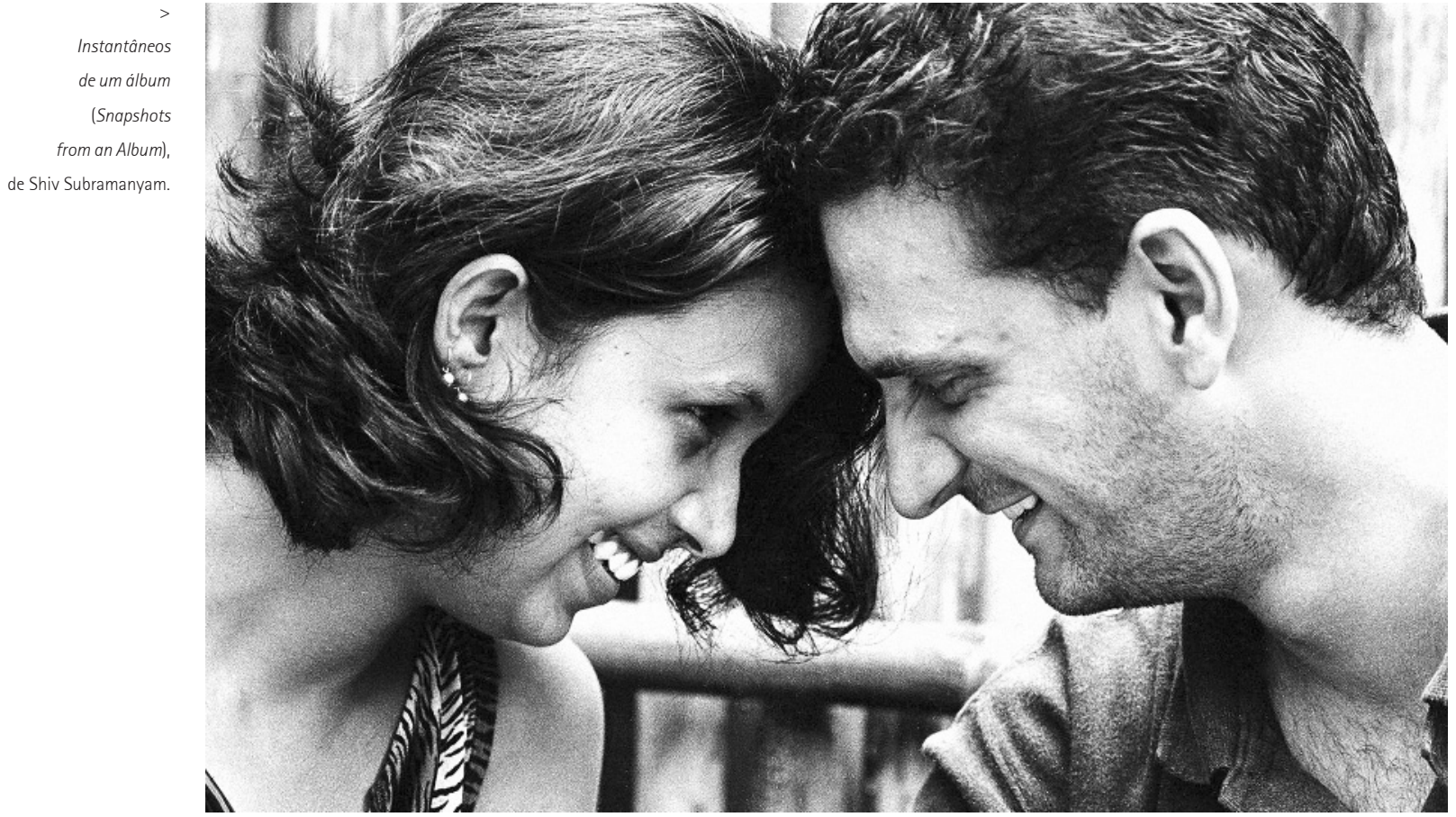

e protegido, chamado Nanhu. Casa Doongaji (Doongaji House, 1978), de Cyrus Mistry, é sobre um casal Parsi que vive num edifício quase em ruínas chamado "a casa Doongaji". A peça foi um enorme sucesso na sua estreia, mercê também da encenação de Toni Patel, uma figura importante do teatro indiano em inglês durante os anos setenta e oitenta. Por último, Legado de raiva (Legacy of Rage), de Cyrus Mistry, foi encenada por Joy Fernandes em 2005 e ocupa-se das trágicas reviravoltas na vida de uma família do Leste da Índia. Embora a encenação não tenha correspondido ao que se esperava, a peça revelouse uma experiência louvável em termos da intriga, da caracterização e da fineza da sua estrutura.

Gurcharan Das pertence à mesma geração de Partap Sharma e do Dr. Gieve Patel, tendo sido responsável, até à data, pela composição de três peças. Larins Sahib foi mesmo apresentada no âmbito do Festival Fringe de Edimburgo, numa produção dirigida por Rahul da Cunha, um outro nome importante no teatro indiano em inglês. A acção da peça decorre no período após a morte de Ranjit Singh, quando os ingleses chegaram ao Punjab, e ocupase da alteração das relações entre os britânicos e a população do Punjab antes da criação da Índia britânica.

0 número de peças originais indianas em inglês tem aumentado consideravelmente desde o início dos anos noventa. Tendo começado a escrever para teatro no final da década anterior, Mahesh Datani é habitualmente considerado como uma das mais importantes vozes contemporâneas. Tendo já visto três das suas peças Dança como um homem (Dance Like a Man), Soluções finais (Final Solutions) e Tara -, diria que o seu trabalho revela sobretudo um talento especial na construção dramática: particularmente hábil na estruturação dos acontecimentos, mostra-se igualmente capaz de inserir as suas personagens na paisagem sociocultural.

Manjula Padmanabhan vive em Dehli e é autor de peças como Colheita (Harvest) - que arrecadou um prémio Onnasis - e Fogos escondidos (Hidden Fires), que se ocupa dos extremismos associados ao "comunalismo" e foi representada em Mumbai durante a edição anual do festival de teatro Prithvi, em 2006.

A contribuição de dramaturgos contemporâneos de Mumbai é muito importante para a expressão que o teatro indiano em inglês conquistou na cidade. Acrescente-se que estes dramaturgos são também encenadores muito competentes, frequentemente responsáveis pela encenação das suas próprias peças.

Ramu Ramanathan, embora subestimado, é de longe o meu dramaturgo indiano favorito a escrever em inglês, sobretudo pela sua capacidade de assegurar uma visão da experiência pan-indiana, mesmo quando as suas peças se ocupam de pessoas e de questões muito específicas. Pelo menos sete das suas peças deveriam figurar em qualquer discussão da situação actual do teatro indiano em inglês: 0 rapaz que deixou de sorrir (The Boy Who Stopped Smiling), Recolher obrigatório (Curfew),

Colaboradores (Collaborators), 3 Sakina Manzil, Amigo (Yaar), Qual é a capital de Manipur (What's the Capital of Manipur) e a mais recente Algodão 56, Poliéster 84 (Cotton 56, Polyester 84). Foi, contudo, Mahadevbhai (1892-1942) que assegurou o sucesso de Ramu como dramaturgo.

Estreada em 2002, a peça tem sido encenada várias vezes com sucesso. Interpretada pelo actor Jaimini Pathak, Mahadevbhai... torna a história algo de contemporâneo e ao fazê-lo recupera uma importante tradição que tende a ser obliterada pelos fenómenos do ódio e preconceito. A forma escolhida é a do contador de histórias, em que um único actor assegura a representação de diversas personagens. A simplicidade do espaço cénico torna a apresentação da peça possível em qualquer lugar. Todas as peças de Ramu surgem marcadas por uma profunda investigação e uma preocupação pelos grupos menos favorecidos da sociedade indiana. 0 estilo de representação combina habitualmente narrativa, diálogo, canções, música e um humor inimitável. Ramu é o que se pode chamar um criador teatral completo, profundamente envolvido com o teatro e todas as actividades que lhe dizem respeito. É uma pena que uma peça tão importante como 

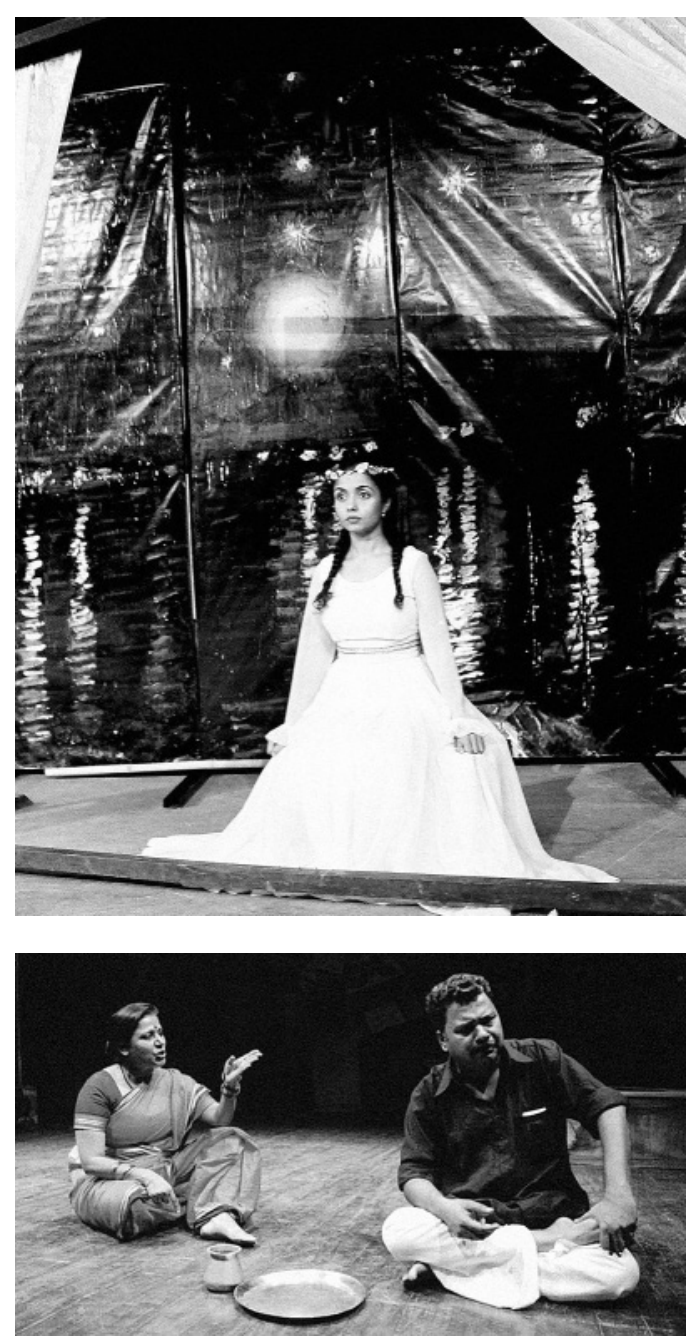

Colaboradores tenha sido ignorada, mas sem dúvida que se trata de um dramaturgo que deixará uma marca única no teatro indiano, e não só no de expressão inglesa.

Shiv Subramanyam é mais conhecido pela sua colaboração com o realizador Vidhu Vinod Chopra no argumento do filme Parinda. Para além de ter participado como actor em muitos espectáculos, Shiv começou a escrever para o teatro em 2000. 0 seu monólogo Cinco minutos para o Sr. Chaterjee (Five Minutes for Mrs. Chaterjee) foi encenado por Vikram Kapadia no âmbito do espectáculo Going Solo Il, composto unicamente por monólogos. Instantâneos de um álbum (Snapshots from an Álbum, 2001) foi a sua primeira peça longa: embora com alguns bons momentos, trata-se de um exercício nostálgico cujas sucessivas reviravoltas não chegam a atingir a desejável profundidade.

0 envolvimento de Vikram Kapadia com o teatro começou em 1981, quando concluiu a sua formação numa escola de representação na cidade, dirigida por Roshan Taneja. Em 1987, criou a sua própria companhia, Masque. A sua primeira comédia negra em dois actos, De volta ao que era dantes (Back with Equal), estreou no festival de teatro Prithvi em 2002 e foi recentemente publicada pela Sahitya Akademi, uma organização de apoio às artes e à cultura de âmbito nacional.

Zubin Driver pertence à mesma geração de Ramu, Shiv e Vikram, tendo igualmente começado a fazer teatro nos anos oitenta. Zubin escreveu uma série de peças originais, a última das quais se chama Pessoas desaparecidas (Missing People). Embora bem representados, os três monólogos que compõem a peça tornam-na excessivamente palavrosa. Tendo também visto A peça verme (The Worm Play), posso talvez avançar que as peças muito verbosas de Zubin se caracterizam pela angústia existencial.

Existem muitos exemplos de boas adaptações na história do teatro indiano, que não se restringem ao domínio do teatro em língua inglesa. Neste último domínio, destacaria três peças, que são o resultado do esforço de três encenadores particularmente bem sucedidos e parte integrante da cena teatral contemporânea em Mumbai.

Naushil Mehta é mais conhecido como encenador do que como dramaturgo. Contudo, assegurou a tradução e adaptação de diferentes obras tanto para guzerate como para inglês. Uma noiva adequada (A Suitable Bride) foi a sua adaptação do romance Kimball Rabenshood, de Madhu Rye - um escritor guzerate fixado nos Estados Unidos e tornou-se umas das maiores histórias de sucesso do teatro indiano. A história gira em torno de um jovem guzerate que vem dos Estados Unidos para a Índia em busca de uma mulher que corresponda ao seu horóscopo. A actriz Seema Kapoor interpretava doze diferentes mulheres, relativas aos doze signos do Zodíaco.

0 nome de Quasar Thakore Padamsee está ligado à história ilustre do primeiro grupo de teatro indiano em inglês da cidade, o já referido Theatre Group, fundado em 1941 por Bobby Sultan Padamsee, responsável pela encenação do primeiro espectáculo da companhia, Macbeth. Inicialmente instalado no Colégio de S. [Francisco] Xavier, o grupo entretanto desactivado continua a exercer uma enorme influência através da personalidade de um dos seus principais elementos, o outrora guru da publicidade Alyque Padamsee, e do seu sucessor na nova geração, o QTP ou Quasar Thakore Productions, o mais reconhecido grupo de teatro indiano em inglês, não só na cidade, mas também noutras partes do pais. O OTP é igualmente responsável por um festival anual de teatro para a juventude, o Thespo, que se estende de Mumbai
A gaivota,

de Anton Tchekov, produçăo da companhia Working Title.

Algodão 56, Polyester 84 (Cotton 56, Polyester 84) de Ramu Ramanathan, enc. Sunil Shanbag (Nagesh Bhonsle e Charusheela Vacchani). 


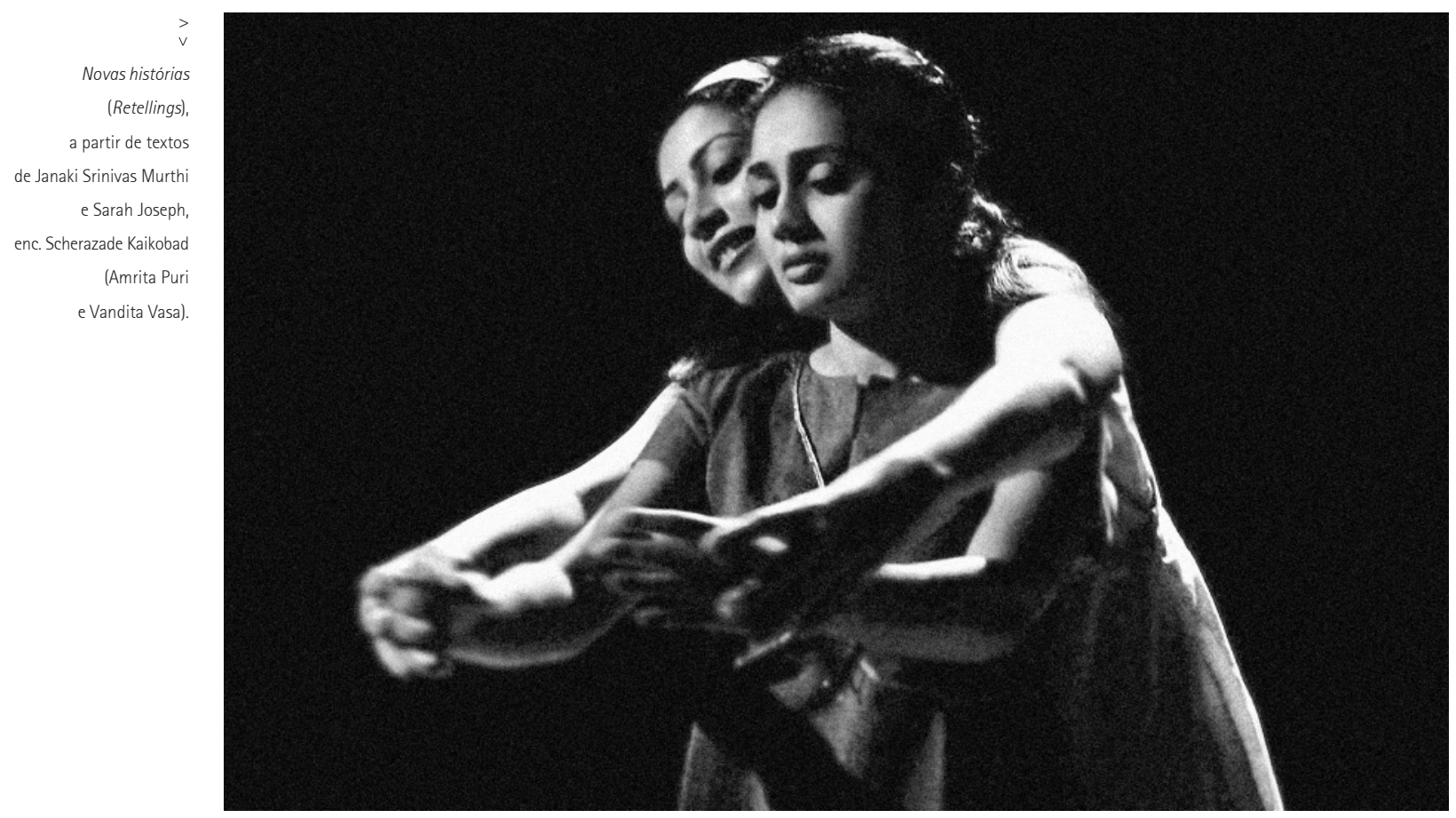

até Bangalore. Mais conhecido como encenador, a sua adaptação de $A$ casa de Bernarda Alba como Khajitabai of Karmali Terrace conseguia transmitir uma sensibilidade verdadeiramente indiana.

A companhia de Rahul da Cunha, Rage, fundada com os actores Shernaz Patel e Rajit Kapoor, é uma das companhias mais bem sucedidas e populares de teatro inglês na cidade. Também mais conhecido como encenador, Rahul escreveu as peças Turma de 84 (Class of 84) e Pune Highwaye adaptou Eu não sou Rapaport (I Am not Rapaport), de Herb Gardener, como Eu não sou Bajirao ( Am not Bajirao), numa produção de grande sucesso, devido sobretudo ao trabalho dos dois intérpretes principais, Boman Irani e Sudhir Mishra. A linhagem teatral de Rahul recua também ao Theatre Group, do qual o seu pai e tio foram membros. A sua companhia, Rage, conquistou um merecido destaque por ter criado o festival anual Writer's Bloc, organizado em colaboração com o Royal Court londrino e destinado a encorajar a escrita de novas peças.

Entre as formações contemporâneas mais jovens, existem ainda outros exemplos, como a The Industrial Theatre Company e a The Company Theatre, cujas produções se destacam sobretudo pelo trabalho cenográfico e de desenho de som e luz. Enquanto experiências com a linguagem, a forma e a estrutura, os seus espectáculos caracterizam-se por um grande apelo visual e estético, incluindo, por vezes, a colaboração com artistas plásticos com vasta experiência no domínio das instalações.

Para além das muitas traduções para inglês de peças originalmente escritas em línguas regionais, nenhuma discussão sobre o teatro indiano em inglês ficaria completa sem uma referência a Satyadev Dubey, um dos pioneiros do teatro moderno na İndia. Embora seja sobretudo um encenador, tão à vontade nas culturas hindi como marata, Dubey também escreveu algumas peças, entre as quais Namora nos teus sonhos (Flirt in Your Dreams), uma ficção autobiográfica que, além de muito divertida, ilustra bem o cuidado do seu autor com o uso da língua.

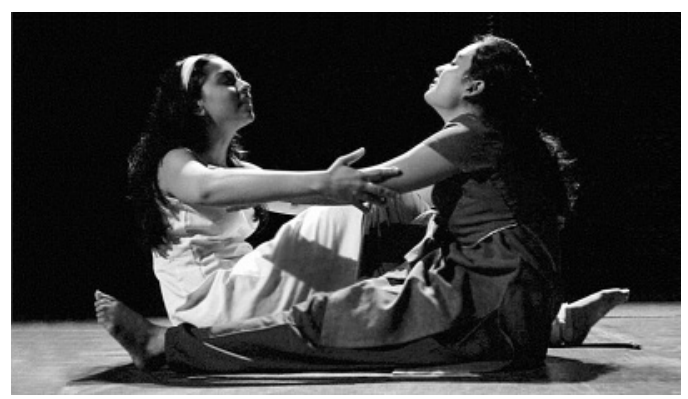

Mas então o que é que assegura o sucesso de uma peça indiana em inglês? Para usar um cliché, eu diria que tudo tem a ver com a capacidade de se encontrar uma capacidade expressiva própria no uso da língua. Quando um crítico perguntou, uma vez, a Mahesh Dattani por que razão ele não escrevia na sua lingua nativa, ele respondeu: "Mas eu escrevo". Embora o número de peças tenha aumentado consideravelmente durante os últimos anos, este indicador não parece suficiente para uma caracterização do estado actual do teatro indiano em inglês. Por exemplo, entre as numerosas peças estreadas no âmbito das primeiras duas edições do referido festival Writers' Bloc, em 2006 e 2007, só duas ou três se revelaram interessantes e promissoras. (É o caso das peças Ácido (Acid), Manteiga e bananas esmagadas (Butter and Mashed Bananas) e Turel, escritas, respectivamente, por Anupama Chandrasekhar, Ajay Krishnan e Swar Thounaojam.)

A pergunta para o futuro poderá ser: neste nosso tempo de globalização e consumismo, será que os jovens dramaturgos indianos em inglês tenderão a distanciar-se das vastas realidades do seu pais ou conseguirão encontrar uma renovada confiança para escrever novas peças com uma dimensão crítica e interpeladora? Teremos de esperar para ver. Entretanto, a única coisa que podemos dizer é que o teatro indiano em inglês conseguiu criar um espaço próprio, merecedor da nossa atenção e reconhecimento.

Tradução de Paulo Eduardo Carvalho 